\title{
La reforma de la Beneficencia en el Cádiz del siglo XVIII: El Hospicio (1785-1808)
}

\section{ARTURO MORGADO GARCIA}

Nuevas actitudes hacia la pobreza se difunden en la España de la Ilustración (1), más acordes con las posturas imperantes desde hacía siglos en los restante's países europeos (2). El punto central radicaba en la fundación de hospicios, instituciones en las que se procedería sistemáticamente al recogimiento de pobres, mendigos, vagabundos y malentretenidos; y esta línea animará los escritos de pensadores como Campillo, Ward, Campomanes o Jovellanos: "el gran encierro", en definitiva, era la solución que se propugnaba para resolver de una vez por todas el problema de la pobreza.

Todo ello no podía menos que afectar al Cádiz de finales del siglo XVIII. Durante el reinado de Fernando VI se había iniciado la construcción de un Hospicio en el Huerto de Zepeda a cargo de la Hermandad de la Santa Caridad bajo la continua protección y asistencia del Marqués del Real Tesoro; y por Real Despacho del 11 de febrero de 1775 dicha institución era puesta bajo la dirección del Consejo

(1) Vid. aparte de las obras clásicas de F. Hernández Iglesias, J. Jiménez Salas o A. Rumeu de Armas, E. Maza Zorrilla Pobreza y asistencia social en España, siglos XVI al XX. (Valladolid, 1987); J. Guillamón Alvarez "Disposiciones sobre policía de pobres: establecimiento de diputaciones de barrio en el reinado de Carlos III", Cuadernos de Historia Moderna y Contemporánea, 1980; J. Soubeyroux Pauperisme et rapports sociaux à Madrid au XVIII éme siècle, 2 vols. (Lille, 1978).

(2) Fundamentalmente J.P. Guiton: La societé et les pauvres en Europe 16e-18e siècles (París, 1974), C. Lis Poverty and Capitalism in the Pre-Industrial Europe 1350-1850 (Londres, 1979), O.H. Hufton "Los horizontes del pueblo" en A. Cobban: El siglo XVII (Madrid, 1988), S. Woolf "Los pobres y la sociedad en el Occidente europeo", Los pobres en la Europa Moderna (Barcelona, 1989). Sobre el "gran encierro", M. Foucault, Historia de la locura en la época clásica (Madrid, 1979). Una buena visión de conjunto en H. Kamen: $E l$ siglo de hierro (2.. edición, Madrid, 1982, pp. 475-486). 
de Castilla, quedando apartado del gobierno el hermano mayor de la Hermandad para ser confiado el mismo a D. Juan de Mérida, presidente interino de la Contratación, y a una junta formada por doce vocales representantes de los estamentos más conspicuos de la ciudad. La Real Presentación del 20 de mayo de 1785 aprobaría unas nuevas ordenanzas de gobierno (3), y a partir de entonces se inicia una nueva etapa en la andadura de dicha institución.

\section{EL REGIMEN DE GOBIERNO}

El contenido de las ordenanzas de 1785 apenas difiere de la normativa contenida en la Real Resolución del 21 de junio de 1780 (4) que daba una serie de líneas generales para el gobierno de los Hospicios. La finalidad del de Cádiz sería así "el socorro de los verdaderos necesitados, su instrucción cristiana y civil, su aplicación al trabajo, el apartar de la vista de los hijos de familia la ociosidad, los vicios y el mal ejemplo, el promover y proporcionar auxilios a los vecinos pobres del pueblo para que puedan, con su aplicación y trabajo, ganar el sustento, adelantar y perfeccionar la industria popular y quitar de raíz los pretextos que fingen los vagos y malentretenidos para permanecer en las calles y plazas públicas, introducirse en las casas para conseguir sus malos fines y engañar a los jueces y a los piadosos, usurpando las limosnas que sólo corresponden a los verdaderos pobres" (5).

El Hospicio se haría cargo de los ancianos, huérfanos, pobres, inválidos y locos. Todos ellos serían alimentados y vestidos, pero su libertad de movimiento estaba sumamente restringida: los ancianos podrían salir los domingos y días festivos, pero si alguno se embriagara, pidiera limosna o cometiera alguna otra falta sería privado por algún tiempo de estas libertades (6). En 1805, dichas salidas eran prohibidas, para permitirse tan sólo las visitas de sus parientes durante los días anteriormente mencionados (7). Por lo que se refería a los niños, solamente podrían pasear los domingos por la tarde y en com-

(3) ANTON SOLE, P.: Situación económica y asistencia social de la diócesis de Cádiz en la segunda mitad del siglo XVIII, Cádiz, 1985, p. 158.

(4) MAZA ZORRILLA, E.: op. cit., pp. 172 ss.

(5) $\mathrm{B}$ (iblioteca) de $\mathrm{E}$ (studios) $\mathrm{G}$ (aditanos), Ordenanzas para el gobierno de la Casa de Misericordia de la ciudad de Cádiz aprobadas por S.M. y Señores de su Real y Supremo Consejo de Castilla, Cádiz, 1785, pp. 3-4.

(6) Ibídem, pp. 7-8.

(7) A(rchivo) G(eneral) de la D(iputación) de C(ádiz), L(ibro) de A(ctas) de la Junta de Gobierno del Hospicio, 514, fols. 160v-161v. 
pañías de sus maestros, en tanto que las jóvenes forzosamente debían disfrutar de sus recreos en los patios de la casa (8). Estas disposiciones experimentaron con el tiempo alguna variación, ya que en 1804 se concedía a los niños el permiso de salir una hora u hora y media diaria tras la puesta de sol a La Caleta, si bien bajo la continua vigilancia de los maestros y cabos (9).

Todos los mantenidos por la institución recibirían una educación cristiana y los santos sacramentos. Los niños serían instruidos en la lectura, la escritura, la aritmética más elemental y, solamente para los más destacados en los estudios, en la geometría y el dibujo. Ancianos e inválidos se dedicarían a cualquier ocupación que les impidiera que sus vidas transcurriesen en la ociosidad. En general, y respondiendo de manera muy clara a las intenciones ilustradas, se observa un gran interés por instaurar el aprendizaje de oficios útiles: todos los residentes en el Hospicio se dedicarían a alguna labor que pudiesen ejercer en la urbe gaditana cuando finalizase el tiempo de estancia en dicha institución (10).

La disciplina reinante era muy rigurosa, recordándonos en cierta medida a las "workhouses" inglesas. Estaba prevista incluso la existencia de un Departamento de Corrección de Costumbres (11) al cual serían destinadas las mujeres que diesen escándalo público y los hombres destacados por su pereza o sus viciosos hábitos, los hijos desobedientes o irrespetuosos con sus padres y los mendigos que pidieran limosna desobedeciendo las Reales Ordenes (12). No obstante, la corrección de costumbres no debía dar resultados excesivamente eficaces, expresando en ciertas ocasiones los miembros de la Junta la necesidad de un mayor rigor: en 1797 se proponía fundar un departamento para mujeres jóvenes prostituidas "instruyéndolas en las labores de manos propias de su sexo a fin de que puedan sostenerse honestamente" (13), ese mismo año Cayetano Huarte y Pedro Gómez Bueno, ambos vocales de la Junta, proponían la mejora del departamento de corrigendas a causa "del ningún fruto que se experimenta en la mudanza de costumbres por el corto tiempo que están en corrección" (14). Seis años más tarde se proponía formar un Departamento de

(8) B.E.G., Ordenanzas..., p. 8.

(9) AGDC, LA, 516, fol. 109v.

(10) BEG, Ordenanzas..., pp. 10-15.

(11) Era algo muy corriente en todos los Hospicios.

(12) BEG, Ordenanzas..., p. 19.

(13) AGDC, LA 513, fol. 25.

(14) Ibídem, fols. 52-53. 
Adultas en el cual "se destinasen cierta clase de jóvenes que envía el gobierno las cuáles ni pueden ponerse entre las educandas de esta casa ni deben estar en la corrección recibiendo los malos ejemplos que dan las reclusas en ella" (15). En 1805, finalmente, se acordaba ceder al Gobernador de la ciudad una parte del edificio a fin de que éste estableciera un departamento "donde se corrigiesen hombres jóvenes y mujeres que incurren en la embriaguez, ociosidad o son mendigos reincidentes que no deben venir a la casa por no ser suficiente castigo" (16).

Se establecía separación de sexos y edades, si bien los pobres casados y con hijos pequeños tenían derecho a vivir junto a sus familias. Comida y vestuario estaban limitados a lo justo para proporcionar la subsistencia y el abrigo más imprescindibles. Se realizaría semanalmente una revista del trabajo realizado y se instaura un sistema de primas a la productividad merced al cual los niños que ganaran con su trabajo más de lo que correspondía a su manutención recibirían de parte de la Junta de Gobierno lo que su aplicación mereciera. Podían abandonar la casa todos aquellos pobres que recobraran la salud o consiguieran personas que los mantuviesen, aunque en el caso de los más jóvenes se examinaría con suma atención los destinos que les eran ofrecidos: los niños serían enviados a trabajar con artesanos y se procuraría casar a las niñas con menestrales aplicados y de buenas costumbres, proporcionando la Junta la suma necesaria para la dote (17).

Es de justicia decir que la institución hizo cuanto estuvo en su mano para proporcionar a los jóvenes a su cargo los medios oportunos para mantenerse dignamente cuando saliesen de la misma. En 1788, el Departamento de Jóvenes exponía la necesidad de proporcionar salida en los buques del comercio de Indias a Juan Gallegos y Juan García y remitir a su padre a Ignacio Ximénez a fin "de darle oficio a éste y facilitar a los otros un destino proporcionado a su inclinación y genio" (18). Ese mismo año se acordaba aprobar la salida de uno de los muchachos de la casa por haberse instruido en el arte de la carpintería lo suficiente como para poder ganarse la vida y establecerse por su cuenta, costeándole además la compra de las herramientas (19). En 1789 se resolvía realizar todas las diligencias oportunas para que los jóvenes instruidos ingresaran en las fábricas de lona existentes

(15) AGDC, LA 515, fols. 91-v.

(16) Ibídem, fol. 109v.

(17) BEG, Ordenanzas..., pp. 33-35.

(18) AGDC, LA 509, fol. 20v

(19) Ibídem, fol. 52. 
en el Real Arsenal de La Carraca (20), acordándose al año siguiente solicitar a la dirección de dicha fábrica la admisión como operarios de todos los muchachos capacitados en el manejo de los telares de algodón y demás oficios practicados en dicho arsenal (21). El vocal Francisco Huarte llegaba en 1797 a proponer que los niños instruidos en la aritmética y la geometría fuesen admitidos en el Colegio de San Telmo de Sevilla (22), solicitud que era negada por Su Católica Majestad, si bien Carlos IV acordaba que tuviesen preferencia en la solicitud de "aplicación a maestranza jóvenes de la tropa de marina o enseñanza de marineros" (23).

El gobierno del Hospicio estaba a cargo de una Junta presidida por el gobernador de la ciudad y formada por doce vocales: dos regidores perpetuos del cabildo municipal gaditano, un representante del cabildo catedralicio, uno de los curas de la Santa Iglesia Catedral y ocho vecinos "de conocido celo, talento y caudal". Todos los vocales serían perpetuos y se alternarían mensualmente en la vicepresidencia de la Junta, siendo el presidente el Juez Supremo de todos los asuntos referidos a la institución, estando a cargo de la Junta el celar sobre el cumplimiento de las ordenanzas, la calidad de los alimentos, la selección de los empleados y la administración económica (24). Los doce primeros vocales fueron Francisco Huarte y Angel de Villalta, ambos regidores perpetuos; 'el racionero Cayetano María de Huarte; el cura Josef de Villar y Vago; los condes de Quinta Alegre y Villamar; y los comerciantes Roque de Aguado, Josef Antonio Gutiérrez de la Huerta, Matías Fernández Pérez, Miguel de Yribarren, Juan Francisco de Leseta y Manuel Sáenz de Tejada (25). Las juntas se celebraron en los primeros años con una gran regularidad, si bien en 1795 el gobernador Joaquín de Fondeviela proponía la formación de una junta restringida formada por dos vocales y el vicepresidente que se reuniría mensualmente para aprobar las solicitudes de ingreso en la Casa, las cuales serían remitidas al Secretario para que éste diera cuenta a la Junta General de quiénes habían sido admitidos (26). Estas juntas, empero, serían suprimidas dos años más tarde a fin de evitar "los perjuicios que de la retardación de las juntas podrían experimentar los pobres" (27).

(20) AGDC, LA 510, fol. 43v.

(21) AGDC, LA 511, fols. 3-5.

(22) AGDC, LA 513, fol. 9.

(23) Ibídem, fol. 36.

(24) BEG, Ordenanzas..., pp. 22-26.

(25) AGDC, LA 507, fols. 4v-5.

(26) AGDC, LA 512, fol. 76.

(27) AGDC, LA 513, fol. 8v. 
Fueron muy pocos los conflictos de carácter jurisdiccional a los que hubo de enfrentarse la institución. Un Real Despacho dictado por el Consejo de Castilla el 7 de marzo de 1788 prohibía a la Hermandad de la Santa Caridad se inmiscuyera en los asuntos internos del Hospicio (28), si bien en 1786 el administrador de la Casa, Fernando Maestro de Cubo y Romero, que ostentaba dicho cargo desde 1775, exponía cómo en 1780 sus facultades habían sido muy limitadas por la Junta y la necesidad de que se aumentaran sus competencias en razón de "la decadencia del Hospicio, indepedencia de sus subalternos, falta de asistencia de los pobres, las quejas frecuentes por la escasez de ración, su mal condimento y falta de vestido... y que las manufacturas y fábricas están a discreción porque los elaborantes entran y salen a su antojo" (29). La Junta, empero, desestimó por completo sus razones, acordando en 1787 relevarle de todas sus funciones y concederle la suma de 400 ducados anuales que disfrutaría mientras no encontrase otro empleo (30).

Todos aquellos individuos que desearan ingresar en el Hospicio debían solicitarlo previamente a la Junta. Ya desde el principio se intentó evitar la comisión de cualquier fraude al respecto, y en 1787 se acordaba que quienes quisieran ser admitidos debían adjuntar a su solicitud su partida de bautismo en la que constara ser naturales de la ciudad o un certificado de cumplimiento pascual que probara su residencia en la misma, los huérfanos remitirían certificación de entierro de sus padres, y en cualquier caso, los curas redactarían las pertinentes certificaciones de pobreza (31). También se daba el caso de que fueran conducidos a la casa los vagabundos detenidos en las levas realizadas periódicamente en la ciudad, siendo destinados al manejo de las bombas, la limpieza de la casa o trabajos de albañilería, desterrándose de la urbe a todos aquellos que no fueran naturales o vecinos de la misma (32), disposición esta última que se reiteraría en 1806 (33).

A pesar de la existencia del Hospicio siguió persistiendo en la ciudad un elevado número de mendigos y vagabundos, contando con numerosas noticias al respecto; en 1798 se exponía cómo "en vista del crecido número de pordioseros lisiados y en aptitud de trabajar que

(28) AGDC, LA 509, fol. 18v.

(29) AGDC, LA 508, fols. 22-29.

(30) Ibídem, fols. 51-52.

(31) Ibídem, fols. $45-46 \mathrm{v}$.

(32) Ibídem, fol. 50.

(33) AGDC, LA 516, fol. 13v. 
abusando de la tolerancia se han entregado a vagos se trató de la recolección de los que tengan legítimo derecho y de la expulsión de los demás" (34). Cuatro años más tarde se solicitaba al gobernador se procediera a la expulsión de los mendigos forasteros (35). Pero una urbe cruelmente azotada por la crisis económica como lo fue el Cádiz de los años noventa del siglo XVIII no podía enfrentarse a este problema con garantías de éxito, y en algún momento observamos incluso un velado intento de restringir el acceso de pobres al Hospicio: en 1800, el vocal Francisco Huarte proponía la admisión de los pobres naturales o vecinos de la ciudad que carecieran de familia que asegurara su manutención, permitir la existencia de los pobres vergonzantes mientras no pidieran limosna públicamente y que los menestrales sin trabajo practicaran ocultamente la mendicidad, prohibiéndose empero esta práctica a los jóvenes. Exponía además las ventajas de las levas de vagabundos, ya que "la práctica ha hecho ver en otras ocasiones que apenas se publicaba la reclusión y se cree que ha de sostenerse con constancia se separan de la ciudad todos los mendigos de profesión y se retiran a los pueblos inmediatos. También se quitan de la vista y aún de mendigar todos los vecinos que por vicio, costumbre o utilidad se dedicaban a la profesión de la limosna de modo que será mucho menor de lo que se cree el número de los que se recluyen", insistiendo en la necesidad de aleccionar a la población para que "aplique la limosna que empleaba en éstos a favor de sus convecinos que ha amparado y socorrido el Hospicio" (36).

La asistencia espiritual del Hospicio correspondía al obispo, que delegaría esta función en los capellanes nombrados para tal efecto (37). En 1785, el prelado José Escalzo y Miguel y el conde O'Reilly, gobernador de la ciudad, firmaban un acuerdo por el cual se disponía la existencia de dos capellanes en la casa que residirían en la misma y tendrían como obligaciones el decir misa, administrar los sacramentos de la confesión y la eucaristía, preguntar el catecismo a los niños los días festivos y enseñar el Catecismo de Fleury (38). Una visita pastoral realizada en 1790 exhortaba a los capellanes a que cumplieran con más celo sus obligaciones, encargando al director espiritual de la Casa comprobara si aquéllos cuidaban de la instrucción en la doctrina cris-

(34) AGDC, LA 513, fols. 49v-50.

(35) AGDC, LA 515, fol. $22 \mathrm{v}$.

(36) AGDC, LA 514, fols. 23v-24v.

(37) BEG, Ordenanzas..., p. 21.

(38) A(rchivo) D(iocesano) de C(ádiz), Secretaría, leg. 36. 
tiana, la frecuencia en la asistencia a los sacramentos y la práctica de ejercicios espirituales (39). No obstante, la asistencia espiritual de la Casa debía ser bastante deficiente, ya que en 1800 el vocal Cayetano Huarte, director espiritual de la institución, exponía la necesidad de enviar como confesores a religiosos de las distintas comunidades monásticas de la ciudad ante la falta de capellanes (40).

El número de internos en el Hospicio fue siempre bastante elevado. En 1787 había un total de 830 (41), que en 1800 serían solamente 693; entre ellos 62 ancianos, 171 ancianas, 139 niños, 203 niñas, 33 "personas de matrimonios", 43 dementes y 34 sirvientas y empleados (42), existiendo los departamentos de pobres ancianos, pobres ancianas, niños, niñas, locos y corrigendos (43). No sabemos hasta qué punto era confortable la vida de los mantenidos por la institución: cuando en 1786 la Junta exponía la situación del Hospicio reconocía, no sin cierta dosis de autocomplacencia, cómo "se ve en el día extinguida la mendiguez (situación que duraría, como hemos visto anteriormente, bastante poco), socorridos los pobres de ambos sexos y matrimonios, recogidos los muchachos y muchachas, recibiendo una educación cristiana y política con la frecuente y profunda instrucción en la doctrina y máximas de religión y en la asidua aplicación al trabajo en que se ocupan mediante el establecimiento de manufacturas oportunas, artes y oficios arraigados ya en la casa" (44), pero ello contrasta con las declaraciones realizadas por el administrador de la casa ese mismo año (45). Es cierto, no obstante, que solamente hemos recogido un caso flagrante de corrupción en los Libros de Juntas, siendo éste la denuncia realizada en 1786 contra algunos individuos que se dedicaban a vender al exterior las hogazas de pan repartidas durante las comidas (46).

No se puede, empero, negar a los miembros de la Junta una dedicación y una entrega que en ciertos momentos raya en la filantropía: en 1787 los vocales decidían otorgar motu propio un préstamo de 600.000 reales a fin de hacer frente al déficit sufrido por la Casa (47),

(39) ADC, Secretaría, leg. 506, "Año de 1790. Visita General".

(40) AGDC, LA 514, fol. 29.

(41) ANTON SOLE, P., op. cit., p. 159.

(42) AGDC, LA 514, fol. 100.

(43) AGDC, LA 507, fols. 51v-52.

(44) AGDC, LA 507, fol. 76v.

(45) Vid. supra.

(46) AGDC, LA 507, fol. 112v, y lib. 508, fols. 1-3.

(47) AGDC, LA 508, fol. 14v. 
en tanto que la acción de algunos vocales, como Miguel de Yribarren en el ramo de manufacturas, y de Cayetano Huarte en el de Niñas, fue incansable: cuando en 1806 fallecía este último, los miembros de la Junta exponían cómo "se dedicó al servicio de los pobres desde el tiempo en que la Hermandad de la Caridad dirigía esta casa.... dio a los pobres pruebas de su caridad y amor empleándose con interés en su servicio, el Departamento de Niñas de cuya diputación estaba encargado fue donde más desahogó su caridad pues haciéndose cargo de que la mayor parte de estas infelices son huérfanas y otras por su desgraciada suerte ni aún conocen a sus padres se propuso ejercitar con ellas este oficio amoroso: las trataba como tal, no omitía medio alguno para mejorar sus costumbres y darles una instrucción sólida en la religión. No se limitaba su caridad al tiempo que estaban estas jóvenes bajo su dirección pues las socorría y auxiliaba en todas ocasiones acreditándoles siempre el interés caritativo con que las miraba empleando la mayor parte de sus rentas en éstas. A su celo y limosnas deben muchas la conservación de sus vidas, otras haberse librado de la prostitución y varias hallarse de religiosas en distintos conventos, puede decirse con verdad que dio sus últimos alientos por los pobres, pues hasta pocas horas antes de su muerte estuvo entre ellos, empleado en su servicio" (48).

Este celo de los miembros de la Junta se plasma también en la organización de la asistencia médica de los pobres: durante la epidemia de fiebre amarilla de 1800 solamente fallecieron 51 de los 560 enfermos existentes (49), en tanto que en el resto de la ciudad el porcentaje de difuntos fue mucho más elevado (50) y en 1804 se tomaron una serie de providencias para prevenir el surgimiento de enfermedades infecciosas, acordándose que los mendigos se mudaran periódicamente de ropa, que sus habitaciones estuvieran continuamente ventiladas y que se lavaran las mismas con agua y vinagre todos los días (51). Normalmente, los individuos que caían enfermos eran enviados al Hospital de San Juan de Dios o al Hospital de Mujeres de Nuestra Señora del Carmen en función de su sexo, si bien en 1803 se disponía

(48) AGDC, LA 516, fols. 12v-13v.

(49) En julio de 1801 se calculaba que se curaron 509 personas, murieron de la epidemia 51 , de otras enfermedades 10 , se curaron en los hospitales 42 , murieron en los hospitales 15, murieron con sus familias 5, quedando por pasar la epidemia 61 (AGDC, LA 514, fol. 100).

(50) Vid. una relación de la epidemia en AGDC, LA 514, fols. 73-81v.

(51) AGDC, LA 515, fol. 158v. 
el establecimiento de una enfermería "para los pobres ancianos que adoleciendo de males habituales no son admitidos en el hospital" (52).

\section{LA SITUACION ECONOMICA}

Uno de los grandes hándicaps a los que hubo de enfrentarse el Hospicio radicaba en la debilidad de sus bases económicas: las ordenanzas de 1785 prescribían que las mismas serían las asignaciones voluntarias proporcionadas por el obispo, el cabildo, el clero, los vecinos y los gremios de la urbe gaditana; y el derecho de un real por cada fanega de trigo que se consumiera en la urbe (53). Los ingresos de la institución se caracterizan, en líneas generales, por su variedad, y por basarse fundamentalmente en las limosnas concedidas por los gaditanos y los arbitrios aplicados por la monarquía (cuadro 2).

El capítulo "fincas, tributos y patronatos" jamás constituyó la base económica del Hospicio, si bien a medida que transcurre el período de nuestro estudio su importancia tiende a aumentar: garantizan el $9,6 \%$ de los ingresos en $1785-1789$ y el $21,2 \%$ en $1805-1807$. El Hospicio era propietario de una veintena de casas y asesorías y de una atahona situadas en la urbe gaditana, percibía los réditos de algunos censos y gozaba además de parte de los ingresos de los patronatos de obras pías fundados por Julián Rodríguez Duro, Josef Gutiérrez, Juan Fragela, Domingo Manuel Rendón y Nicolás Fernández del Castillo, todos ellos administrados por el cabildo catedralicio (54). En 1788 se acordaba labrar junto a la Casa "una plaza o anfiteatro" dado "la afición que se ha reconocido al inocente y honesto divertimiento del juego de gallos" (55), concediéndose en 1791 comisión a Joseph Retortillo para que comprara un reñidero de gallos en Puerto Real, lo desarmara y lo instalara junto al Hospicio (56).

Mayor importancia para las finanzas de la institución tuvieron las limosnas, que garantizaban por término medio entre la quinta parte y un treinta por ciento de los ingresos totales, si bien su volumen estaba muy relacionado con la marcha de la coyuntura económica. Los donativos y los legados recibidos por el Hospicio fueron continuos: en 1787, doña Josefa Niño dejaba 2.000 pesos (57); en 1789 el vicecónsul

(52) Ibídem, fol. 116.

(53) BEG, Ordenanzas..., p. 5.

(54) AGDC, lib. 527, Réditos de casas, fincas y tributos (1784-1796).

(55) AGDC, LA 509, fol. 33v.

(56) AGDC, LA 512, fol. 19v.

(57) AGDC, LA 508, fol. 16v. 
y diputados de la Nación Francesa donaron 30.000 reales (58); en 1791, el prelado Antonio Martínez de la Plaza resolvía proporcionar la suma de 50 pesos mensuales (59); en 1797, Micaela de Herrera Dávila donaba en su testamento 15.000 reales (60); en 1798, el antiguo gobernador de la ciudad, Joaquín de Fonsdeviela, fallecido ese mismo año, aportaba la respetable suma de 100.000 reales (61)... los responsables de la Casa eran sumamente conscientes de que la buena marcha del centro dependía en gran medida de estos arbitrios, y periódicamente organizaban campañas de propaganda o animaban a los gaditanos a que proporcionaran fondos para el Hospicio: en 1786 se exponía la conveniencia de destinar agentes en La Habana y Cartagena de Indias que pidieran limosna por la Casa por acoger ésta a pobres de tan lejanas regiones (62), al año siguiente, el gobernador Joaquín de Fonsdeviela convocaba a los diputados, veedores y demás representantes de los gremios de la ciudad "a quienes les hizo presentes las ventajas que experimentaban de esta Casa de Misericordia las cuales se refundían en los individuos de dichos gremios quienes experimentaban los auxilios que ofrece este albergue caritativo así en las miserias de su ancianidad como en la viudedad de sus mujeres y orfandad de sus hijos por cuyas razones parece que debían ser los primeros interesados en sostener esta casa asignando la limosna que su caridad y proporciones les dicte en equivalente a la que daban a los muchos mendigos que antes se les presentaban" (63); en 1799 se resolvía, a fin de hacer frente a la mala situación económica del Hospicio, pedir pan de limosna y nombrar dos o más pobres que recogieran hortaliza en los muelles y carbón en los pesos de Puerto Escondido y Puerta Tierra (64), al año siguiente, los vocales de la Junta acordaron se organizara una cuestación de pan entre los vecinos de la urbe gaditana (65)...

La base económica del Hospicio, no obstante, venía dada por el capítulo "arbitrios y aplicaciones", que pasa de proporcionar un tercio de los ingresos totales en 1785-1789 a casi la mitad en 1805-1807. Eran de muy variado tenor: el más importante, sin duda alguna, era el dere-

(58) AGDC, LA 510, fol. 26v.

(59) AGDC, LA 512, fol. 17.

(60) AGDC, LA 513, fol. 42v.

(61) Ibídem, fol. 62.

(62) AGDC, LA 507, fol. 73.

(63) AGDC, LA 508, fols. 61-62.

(64) AGDC, LA 513, fol. 86v.

(65) AGDC, LA 514, fols. 62-63. 
cho de un real por cada fanega de trigo que se consumiera en la ciudad, concedido en virtud de la Real Presentación del 9 de febrero de 1784. Un decreto del 14 de diciembre de 1787 ordenaba que ninguna persona ni comunidad secular o eclesiástica estuviera exenta de pagar dicha contribución (66), que sería abolida en virtud de la Real Orden del 17 de marzo de 1808 (67). En 1784-1789 este derecho proporcionó un total de 1.760 .000 reales (68). Pero a ello había que añadir una asignación de 50.000 reales anuales procedentes de la Real Lotería (69), la refacción de las especies de millones consumidas por la Casa y la asignación del Fondo Pío Beneficial según la Real Orden del 24 de agosto de 1801, que en 1802 aportaba 49.484,05 reales (70).

Otras fuentes de ingresos tuvieron menos importancia. Las manufacturas nunca aportaron, ni siquiera en sus mejores tiempos, más de la séptima parte de las rentas totales de la Casa, y su producto disminuyó enormemente desde que en 1798 fuesen abolidas. Tampoco los ingresos de carácter extraordinario supusieron mucho al Hospicio, si exceptuamos los años 1785-1789.

Por lo que se refiere a los gastos, el grueso de los mismos (cuadro 2) siempre vino proporcionado por la manutención y la vestimenta de los residentes en la institución, que constituían el 44\% de los gastos en 1785-1789 y el 76,9\% en 1805-1807. La alimentación de los internos debía ser relativamente escasa, según nos revela un presupuesto realizado en 1787 por el que se disponía que "los de primera clase" recibieran un quinto de hogaza de pan en cada comida, media panilla de aceite, cuatro onzas diarias de carne, pescado los días de vigilia y arroz, garbanzos, frijoles, fideos y habas en distintos días del año. A los de "segunda clase" se les proporcionaría pan, carne, vino, arroz, garbanzos, frijoles, fideos, habas y bacalao, y a los de "tercera clase" pan blanco, chocolate, carne, tocino, berza, bacalao, pescado o huevos para segundo plato y menestra, existiendo 725 raciones de primera clase, 33 de segunda y 16 de tercera según nuestros cálculos (71), debiendo corresponder estas últimas a los sirvientes y empleados de la institución, cuya dieta era no sólo más variada sino más abundante: si la ración anual de carne de los "de primera clase" ascendía a 36 libras, esta cifra se elevaba a 96 para los de segunda y tercera clase.

(66) AGDC, LA 508, fol. 70.

(67) AGDC, LA 516, fol. 112.

(68) AGDC, LA 510, fol. 30.

(69) AGDC, LA 508, fol. 42

(70) AGDC, LA 515, fol. 54.

(71) AGDC, LA 508, fols. 33-34v. 
Otros capítulos no supusieron un dispendio excesivamente elevado para la institución. Los salarios y las gratificaciones de los empleados permanecen en niveles constantes, en tanto que las cargas y pensiones del Hospicio suponen un porcentaje despreciable de los gastos. Los gastos extraordinarios tienen importancia en momentos muy concretos, precisamente cuando en el edificio se realizaban obras y reparaciones de envergadura. Por lo que se refiere a los gastos de manufacturas, que comprenden la compra de maquinaria y materias primas y salarios de los maestros artesanos, tras la abolición de las mismas en 1798 apenas gravaron las cuentas de la institución.

La evolución económica del Hospicio (cuadro 1) durante este período se caracteriza por un endeudamiento progresivo. En líneas generales, los años comprendidos entre 1787 y 1796 ofrecen un balance anual superavitario, pero a partir de 1797, debido a la interrupción de los contactos comerciales como consecuencia del bloqueo de la ciudad operado por la armada inglesa (lo que provocaría menos beneficios mercantiles y por consiguiente menos limosnas, amén de privar de un mercado a las manufacturas ofrecidas por la Casa), la situación financiera del Hospicio se vio gravemente amenazada. Tras la firma de la Paz de Amiens en 1802 volverán momentáneamente los buenos tiempos, de manera que en 1803 volvemos a encontrar un nuevo superávit, pero los nuevos enfrentamientos bélicos que sobrevendrán acto seguido provocarán la reaparición de los déficits, si bien todavía en 1807 la Casa tenía un saldo a su favor de unos 58.000 reales de vellón... cifra muy lejana de los más de 100.000 que por término medio se conocieron en los primeros años de la década de los noventa.

Los responsables de la administración económica de la institución procuraron en la medida de lo posible adecuar los gastos del centro a sus ingresos, y no es extraño encontrarnos con medidas de carácter restrictivo: en 1795 se disponía que la ración "de segunda mesa", por ser más costosa que la ordinaria, solamente fuese aplicada a las maestras y a un número limitado de pobres (72), tres años más tarde se resolvía dejar de dar semanalmente "tabaco de polvo" a las ancianas y locas debido a los atrasos de la Casa, a la que faltaban "la entrada de limosnas con motivo de la guerra estando empeñada por los indispensables gastos en la sustentación de los pobres y enseñanza de los jóvenes habiéndose aumentado el número y minorado los auxilios cuando más se necesita" (73).

(72) AGDC, LA 512, fol. 94.

(73) AGDC, LA 513, fol. 60. 


\section{PROYECTOS FALIIDOS DE INDUSTRIALIZACION}

La vitalidad que durante estos años manifestó el Hospicio provocó que el mismo acogiera numerosas iniciativas en su seno. O'Reilly estableció una escuela gratuita de dibujo en la Casa, que llegó a reunir 150 discípulos, con una sala para dibujo y otra para aritmética y geometría, siendo impartidas las lecciones dos horas diarias por la noche (74). No obstante, y debido a los inconvenientes que presentaba el establecimiento de dichas enseñanzas en el Hospicio, la. Real Orden del 20 de junio de 1786 solicitaba se informara acerca de los medios más oportunos para la fundación de una Academia de Dibujo, Aritmética, Geometría y Arquitectura en un lugar más apropiado (75), lo que provocaría a corto plazo la fundación de la Academia de Nobles Artes de Cádiz.

La Real Orden del 27 de noviembre de 1802 disponía la fundación de un hospital para la curación de enfermedades venéreas, aplicando para su creación el impuesto sobre el vino que estaba destinado a la conservación de las lanchas cañoneras (76), arbitrio que fue abolido en 1805 para ser destinado a la formación de un cuerpo de tropa en la ciudad con motivo de una nueva coyuntura bélica (77).

Pero la iniciativa más interesante fue el establecimiento de manufacturas en la institución (78), obedeciendo a los nuevos criterios ilustrados de beneficencia según los cuales los pobres debían ser instruidos en oficios útiles. Los datos que los Libros de Juntas nos proporcionan sobre estas actividades son muy numerosos: en 1786 se suprimía

(74) AGDC, LA 507, fols. 91v-94v.

(75) AGDC, LA 506, fol. 82.

(76) AGDC, LA 515, fol. 61.

(77) AGDC, LA 516, fol. $182 \mathrm{v}$

(78) Vid. las descripciones de BOURGOING, Barón de: "Un paseo por España durante la Revolución Francesa"; GARCIA MERCADAL, A.: Viajes de extranjeros por España y Portugal, tomo 3, Madrid, 1962, p. 1.037; y TOWNSEND, J.: "Viaje a España hecho en los años de 1786 y 1787", Ibidem, pp. 1.546-1.548. El edificio tenía una espaciosa sala provista de herramientas y materiales de trabajo entre los que se contaban 45 telares para tejer y 16 para hacer medias, amén de tornos, bancos y herramientas de carpinteros, torneros, zapateros y sastres, un molino para retorcer y una máquina para hilar y otra para cardar el algodón. El Hospicio proporcionaba a aquellas personas que querían trabajar y no podían ausentarse de sus casas torno y lana, pagándoles por su trabajo, estableciéndose escuelas donde se enseñaban las distintas artes a las que podía asistir cualquiera libremente (PASCUA SANCHEZ, M.J.: "Cádiz y su provincia 1700-1788", Provincia de Cádiz, vol. 2, Sevilla, 1984, pp. 322-323). 
la fábrica de sebo por no dar la misma beneficios (79), en tanto que el vocal Miguel de Yribarren hacía presente que pensaba enviar a dos tiendas acreditadas de la ciudad todos los géneros de algodón e hilo elaborados en la casa, que el fabricante de medias de seda Joseph Pedemonte pensaba instalar doce telares de medias redecillas instruyendo en este arte a doce muchachos, y que un cuerpo militar había propuesto hacer una contrata para elaborar un gran número de pares de medias de algodón (80). Al año siguiente se realizaba una relación de las existencias de efectos vendibles, que fueron valorados en 360.322 reales, en tanto que la maquinaria estaba apreciada en 112.818,23 reales (81). En 1788 se presentaba el alemán Joseph Heckel exponiendo sus intenciones de establecer una fábrica de botones dando la Junta comisión a Yribarren para que examinase sus proyectos (82), aprobándose asimismo el establecimiento del maestro tornero francés Joseph Suretan (83). Ese mismo año Yribarren realizaba una contrata con D. Gerónimo Martínez García comprometiéndose éste a entregar al Hospicio 15.000 varas de bramante crudo cuyo lienzo se destinaría para la fabricación de sacos que sirvieran para el acarreo de trigo al Pósito de la ciudad (84), en tanto que se rechazaba la pretensión de los filipinos Ambrosio de los Reyes y Toribio de San Pelayo de establecer una fábrica de hilados de algodón en virtud "de la corta inteligencia y poco valor de los hilados que hacen" (85) y se establecía el fabricante de medias de algodón e hilo Juan Vilaret con cuatro telares (86). Pero el elevado costo que suponía para el Hospicio la

(79) AGDC, LA 507, fol. 68.

(80) AGDC, LA 507, fols. 104-105v.

(81) Los efectos existentes eran 986 piezas de indianas estampadas, 764 libras de algodón cardado, 2.360 libras de algodón en rama, 2.596 libras y media de algodón hilado y enmadejađo, 1.567 libras de algodón de desperdicios para acolchar, 37 piezas acolchadas, 63 piezas de tejidos de lino y algodón, una pieza de muselina, una pieza de mantelería, cuatro piezas de terciopelo de algodón rayado, 135 piezas de lienzos crudos, 3.682 libras de hilaza e hilo, 450 piezas de ámbar de hilo, 55 calcetas, 4.300 libras de lino, 434 varas y media de encajes, 6 libras y 13 onzas de hilo superior para hacer encajes, $14.811,16$ reales valor de los efectos puestos en las tiendas de Ortiz y Castel (AGDC, LA 508, fol. 19).

(82) AGDC, LA 509, fol. 1

(83) Ibídem.

(84) Ibídem, fol. 9.

(85) Ibídem, fol. 34.

(86) Ibídem, fol. 60. 
implantación de las manufacturas (87) motivó que el 17 de agosto de 1789 la Junta acordara el despido de una serie de maestros artesanos (el maestro zapatero, el maestro cardador y la maestra hilandera), diera por nulas las contratas firmadas con varios fabricantes catalanes y redujera los salarios del maestro de obras bastas de torno, el maestro carpintero, la maestra de hilados, el maestro hilandero, las maestras de encaje y bordados y el maestro tejedor (88), aludiéndose seis años más tarde a la supresión de las maestras de hilado de lino y algodón y la de calcetas y bordado (89).

La Junta celebrada el 30 de octubre de 1798 tomó una resolución de gran trascendencia. El vocal Francisco Huarte exponía cómo las manufacturas establecidas en el Hospicio, a pesar "de que la felicidad del comercio y seguridad de la navegación proporcionaba ventajas y estimulaba a que varios particulares estableciesen fábrica en Cádiz a pueblos del contorno... no se han establecido tantas como debía esperarse" (90), y su implantación había provocado además graves quebrantos económicos a la casa, ya que hasta fines de 1797, los ingresos proporcionados por las mismas ascendian a 2.096.664,19 reales, en tanto que los gastos suponían $3.849 .753,28$, aludiendo a la guerra y al bloqueo inglés como factores que impedían una mayor venta de los géneros producidos en la Casa. La Junta resolvió que a partir del 1 de diciembre cesase la actividad de los talleres, "que no siendo necesarios los acopios de hilados que se hacían para las fábricas se cierre la escuela de externas despidiendo a la maestra y que no se facilite lino ni algodón a las familias del pueblo", que se estableciera en la sala de hilados una escuela de primeras letras y que solamente se permitiera la permanencia del maestro tejedor Juan Vilaret, el maestro carpintero Juan Bomlie y el maestro zapatero Francisco Baquera (91).

La actividad industrial no desaparecería completamente: en 1800 se acordaba enviar una representación al monarca para establecer una

(87) En $1784-1789$, los gastos ascendieron a $1.987 .204,19$ reales: $455.863,17$ se destinaron a la compra de materias primas; $206.836,18$ a la de maquinaria; $744.405,0$ a salarios de maestros; $54.441,10$ a los alquileres de sus casas; $129.328,08$ a los jornales y gratificaciones de los operarios; $190.488,18$ a pinturas y estampados; $15.526,28$ a jörnales de canilleras y $179.314,05$ a hilado de externas (AGDC, LA 510 , fol. 31).

(88) Ibídem, fols. 35-37.

(89) AGDC, LA 512, fol. 52v.

(90) AGDC, LA 513, fols. 80 ss.

(91) Ibídem, fols. $74 \mathrm{v}-78$. 
imprenta en el Hospicio (92), concediendo Carlos IV la fundación de la misma, pudiendo "imprimir mayor número de pliegos de los que se permiten a las demás de esta ciudad" (93). En 1804, el fabricante de peines de marfil, Josef Brito y Barem, de origen portugués, solicitaba establecerse en la Casa manteniendo a una serie de aprendices a su costa, lo que le fue concedido (94). Pero se cerraron completamente las puertas a iniciativas de mayor envergadura: cuando en 1802 el gobernador Tomás de Morla proponía a la Junta la fundación de una fábrica de cigarros, los vocales manifestaron las razones que les movieron al abandono de las antiguas manufacturas y los motivos que les asistían para negarse a la implantación de dicha actividad (95).

¿Por qué fracasaron estos proyectos? Podemos aludir a las mismas razones por las cuales no fructificaron los intentos industrializadores centrados en los Hospicios, a saber, el hecho de que se trabajaba con desgana, de manera intermitente y con rendimientos muy bajos (96), factores a los que, como vimos anteriormente, aludía el administrador Fernando Maestro de Cubo y Romero. A todo ello habría que añadir las causas que provocaron el fracaso de los numerosos proyectos de protoindustrialización habidos en la Andalucía de finales del siglo XVIII: "el descarado coyunturalismo de la empresa, vinculado temerariamente a circunstancias de muy corta duración debidas a problemas internacionales y condiciones de mercado... la ineficacia operativa, al enfrentarse con problemas técnicos, como la importación de material de infraestructura... circunstancias menos claras relacionadas con la idiosincrasia empresarial de la zona, con fracasos en la comercialización de los productos" (97). La implantación de manufacturas en el Hospicio tuvo la mala fortuna de coincidir casi en el tiempo con los inicios de la crisis económica gaditana a causa de los conflictos bélicos que tuvieron lugar en los noventa, jugando el bloqueo inglés, como reconocían los propios responsables de la institución, un papel preponderante: si ni siquiera en los buenos tiempos la Junta hizo grandes

(92) AGDC, LA 514, fol. 61v.

(93) Ibídem, fol. 73.

(94) AGDC, LA 515, fols. 121-v.

(95) Ibídem, fols. $58 \mathrm{v}-60$.

(96) GUTTON, J.P.: op. cit., p. 134.

(97) GARCIA-BAQUERO GONZALEZ, A.: "Andalucía en el siglo XVIII: el perfil de un crecimiento ambiguo"; FERNANDEZ, R. (ed.): España en el siglo XVIII, Homenaje a Pierre Vilar, Barcelona, 1985, p. 394, ofreciendo el autor una selección bibliográfica sobre esta cuestión. 
esfuerzos por asegurar una adecuada comercialización de los productos, exceptuando iniciativas aisladas del vocal Miguel de Yribarren, y en alguna ocasión los fabricados sirvieron tan sólo para ser cedidos a los acreedores de la Casa (98); podemos imaginar lo que habría de suceder en los años de crisis, con una población azotada por el paro, la inflación y las quiebras mercantiles. A falta de un mercado, cualquier iniciativa artesanal se vería abocada al más completo fracaso, y eso fue lo que sucedió.

\section{CUADRO 1 \\ INGRESOS Y GASTOS ANUALES}

\begin{tabular}{lrrr} 
& Ingresos & Gastos & Balance \\
\cline { 2 - 4 } 1785 & $1.098 .642,12$ & $1.385 .888,14$ & $-117.149,06$ \\
1786 & $945.647,11$ & $1.468 .219,33$ & $-522.722,22$ \\
1787 & $1.625 .931,23$ & $969.196,20$ & $134.162,15$ \\
1788 & $1.678 .071,04$ & $1.615 .423,20$ & $196.809,33$ \\
1789 & $1.127 .480,24$ & $1.504 .615,18$ & $-180.324,29$ \\
1790 & $1.531 .203,32$ & $1.248 .978,11$ & $101.900,26$ \\
1791 & $1.236 .588,29$ & $1.095 .862,33$ & $242.626,22$ \\
1792 & $1.108 .699,16$ & $1.056 .092,14$ & $295.233,24$ \\
1793 & $1.135 .290,11$ & $1.186 .459,16$ & $244.064,19$ \\
1794 & $1.078 .463,07$ & $1.271 .086,33$ & $51.440,27$ \\
1795 & $1.107 .328,23$ & $1.145 .517,14$ & $13.252,02$ \\
1796 & $1.068 .263,23$ & $885.959,07$ & $195.556,18$ \\
1797 & $803.172,33$ & $1.129 .185,14$ & $-130.455,31$ \\
1798 & $1.074 .222,14$ & $1.164 .723,15$ & $-220.956,32$ \\
1799 & $942.377,14$ & $842.946,11$ & $-121.525,29$ \\
1800 & $857.063,03$ & $850.276,27$ & $114.739,19$ \\
1801 & $867.311,20$ & $1.048 .546,21$ & $-295.974,20$ \\
1802 & 1.066 .245 & $855.292,20$ & $-85.022,06$ \\
1803 & $1.304 .823,13$ & $1.062 .923,29$ & $156.877,12$ \\
1804 & $820.688,30$ & $991.199,18$ & $-13.633,10$ \\
1805 & $1.103 .751,21$ & 1.074 .658 & $15.460,11$ \\
1806 & $924.697,14$ & $1.021 .852,23$ & $-81.694,32$ \\
1807 & $913.672,20$ & $890.061,07$ & $58.083,19$
\end{tabular}

Fuente: AGDC, L.A. 507-516. Cifras en rs. de vellón y maravedises.

(98) En 1788, por ejemplo, se acordaba que los acreedores "pueda tomar a cuenta de sus créditos los géneros que necesiten y existen en el almacén de manufacturas" (AGDC, LA 509, fol. 16v). 


\section{CUADRO 2 \\ ESTRUCTURA DE LOS INGRESOS Y DE LOS GASTOS}

\section{Ingresos}

Fincas, tributos, patronatos Limosnas

Arbitrios y aplicaciones

Venta de manufacturas

Extraordinarios

\section{Gastos}

Viveres

Vestuario

Manufacturas

Salarios y gratificaciones

Cargas y pensiones

Extraordinario
1785-89

$1790-9$

1795-99

1800-04 1805-07

$\begin{array}{rrrrr}9,6 & 14,1 & 16,3 & 16,3 & 21,2 \\ 26,8 & 19,6 & 20,3 & 30,2 & 24,3 \\ 33,9 & 40,8 & 46,6 & 45,1 & 49,4 \\ 9,5 & 15,4 & 14,3 & 5,6 & 4,0 \\ 19,1 & 9,6 & 2,0 . & 2,6 & 0,3\end{array}$

36,9

52,1

55,6

57,8

69,0

8,0

11,8

20,6

10,4

16,6

12,1

7,9

4,7

6,0

0,2

0,3

23,9

8,8

7,8

2,2

2,8

$9,3 \quad 9,2$

$0,4 \quad, 0,2 \quad 0,3$

$\begin{array}{lll}8,6 & 17,7 & 10,3\end{array}$

Fuente: Ibídem cuadro anterior. 